\title{
St Jude Medical Trifecta aortic prosthesis: Considerations for implantation
}

\author{
W. R. Eric Jamieson, MD, FRCS(C), FACS, FACC
}

See related article on pages 1567-75.

The article in this issue of the Journal entitled "Early Hemodynamic Performance of the Third Generation St Jude Medical Trifecta Aortic Prosthesis" by Phan and colleagues $^{1}$ is an evaluation of safety and hemodynamic performance of the Trifecta aortic prosthesis (St Jude Medical, Inc, St Paul, Minn) in the short term in a meta-analysis of 2549 patients from 13 studies. Phan and colleagues ${ }^{1}$ report acceptable mean gradients and effective orifice areas in all prostheses from 19 to $29 \mathrm{~mm}$.

The St Jude Medical Trifecta was evaluated in a multicenter investigational trial conducted in North America and Europe between 2009 and 2011 and subsequently approved by the US Food and Drug Administration. The analysis by Phan and colleagues ${ }^{1}$ incorporates studies published primarily in 2013 and 2014 and formulated to evaluate the safety and hemodynamic performance in this most recent new aortic bioprosthesis. At the request of the peer reviewers, the article incorporates an introduction to important considerations for implantation.

The design of the prosthesis and the implantation characteristics can both contribute to altered hemodynamic performance of this uniquely designed bioprosthesis. The Trifecta bioprosthesis is designed for supra-annular implantation, with specific design characteristics intended to advance durability but contribute to important characteristics for implantation. The Trifecta is a trileaflet pericardial prosthesis formulated with a titanium stent. The titanium stent is covered with a polyester fabric, which is subsequently covered with porcine pericardial tissue. The prosthesis leaflets are fabricated bovine pericardium mounted externally. The porcine covers on the polyester

From the Division of Cardiovascular Surgery, Department of Surgery, University of British Columbia, Vancouver, BC, Canada; and the Vancouver Coastal Health Research Institute, Vancouver, BC, Canada.

Disclosures: Author has nothing to disclose with regard to commercial support.

Received for publication March 16, 2015; accepted for publication March 23, 2015; available ahead of print April 21, 2015.

Address for reprints: W. R. Eric Jamieson, MD, FRCS(C), FACS, FACC, Department of Surgery, University of British Columbia, 486 Burrard Building, St Paul's Hospital 1081 Burrard, Vancouver, BC V6Z 1Y6, Canada (E-mail: eric.jamieson@vch.ca).

J Thorac Cardiovasc Surg 2015;149:1576-7

0022-5223/\$36.00

Copyright (c) 2015 Published by Elsevier Inc. on behalf of The American Association for Thoracic Surgery

http://dx.doi.org/10.1016/j.jtcvs.2015.03.034 stent and the bovine pericardial leaflets protect from mechanical wear by allowing only tissue-tissue contact. The porcine and bovine pericardium are preserved and cross-linked with glutaraldehyde and treated with the ethanol LINX anticalcification technology (St Jude Medical).

The Trifecta prosthesis is a high-

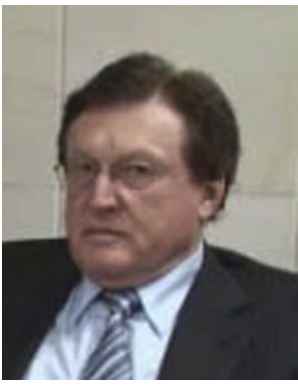
profile valve, and this in combination with the titanium stent can contribute to deformation of the prosthesis at surgical implantation. The valve size selection must be based on the recipient annulus and anatomy of the sinotubular junction. There are several important factors that must be given attention in both selection of the prosthesis size and implantation. Deformation of the titanium stent must be absolutely avoided at prosthesis implantation, because any stent deformation will be permanent and obviously contribute to altered permanent hemodynamics. The sizing of the prosthesis can facilitate this important factor. The sizer for the prosthesis is a double-ended device to size the annulus with a cylinder and a replica of the prosthesis for supra-annular placement. Oversizing of the prosthesis can also be a factor in prosthesis deformation at implantation. The cylinder of the sizer must only pass through the annulus with moderate resistance, and the flanged portion of the sizer, representing the supraannular prosthesis, must never be passed through the annulus. The Trifecta prosthesis must never be oversized, because titanium deformation can be caused by oversizing. If there is any choice between 2 sizes, the smaller of size must be chosen to avoid oversizing and potential prosthesis deformation. The replica sizer will also provide any potential risk of coronary obstruction, because the stent posts must avoid obstruction to the coronary ostia.

In summary, oversizing and deformation of the highprofile stents at implantation are extremely important to avoid deformation of the titanium stent, which will cause permanent implantation characteristics that in turn can cause reduced hemodynamic performance and potentially regurgitation of improperly approximating cusps.

The article documents that $60.3 \%$ of the prostheses are sizes 19 and $21 \mathrm{~mm}$, whereas only $25.1 \%$ are size $23 \mathrm{~mm}$. The documented prosthesis sizes had to be implanted with the documented considerations addressed in this commentary regarding the Trifecta prosthesis. It is of extreme importance to note that the hemodynamics 
remained excellent for all sizes, with a pooled mean gradient of $9.2 \mathrm{~mm} \mathrm{Hg}$ and an effective orifice area of $1.8 \mathrm{~cm}^{2}$.

The St Jude Medical Trifecta pericardial prosthesis must never be oversized, and at implantation the stent post positioning must not be altered, because any altered positioning will result in titanium stent deformation and the potential for altered hemodynamics and bovine pericardial leaflet positioning. The article does indeed document the safety of the prosthesis and excellent hemodynamics of the prosthesis, even for sizes 19 and $21 \mathrm{~mm}$.

\section{Reference}

1. Phan K, Ha H, Phan S, Misfeld M, Di Eusanio M, Yan T. Early hemodynamic per formance of the third generation St Jude Trifecta aortic prosthesis: A systematic review and meta-analysis. J Thorac Cardiovasc Surg. 2015;149:1567-75.e2. 